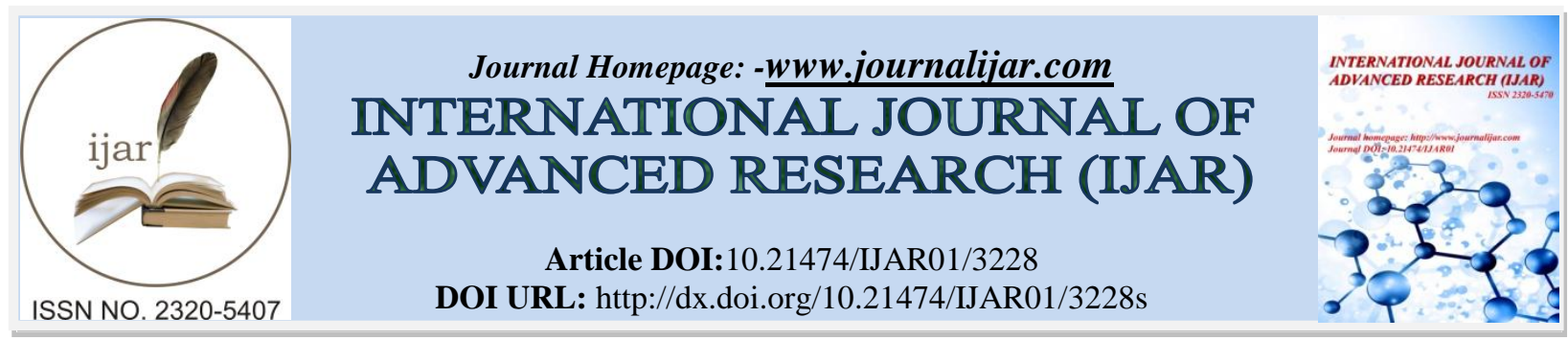

RESEARCH ARTICLE

\title{
ROLE OF SERUM LACTIC ACID LEVEL IN DIAGNOSING MESENTERIC BOWEL ISCHEMIA WITH THE AID OF THE CT ANGIOGRAM.
}

\author{
Khadijah Mohammed Ayoub ${ }^{1}$, Ahmed Haitham Abduljabbar ${ }^{2}$, Sara Ali Sawan ${ }^{1}$, Mawaddah Tallab ${ }^{1}$ and \\ Mohammad Abdulrahim Wazzan ${ }^{2}$. \\ 1. Faculty of Medicine, King Abdulaziz University, Jeddah ,Saudi Arabia. \\ 2. Department of Radiology, Faculty of Medicine, King Abdulaziz University, Jeddah, Saudi Arabia.
}

\section{Manuscript Info}

Manuscript History

Received: 22 December 2016

Final Accepted: 03 January 2017

Published: February 2017

\begin{abstract}
Background: Acute mesenteric ischemia is a syndrome caused by inadequate blood flow through the mesenteric vessels, resulting in ischemia and eventual gangrene of the bowel wall; it is a potentially life-threatening condition. This study aimed to identify the specificity and sensitivity of using lactic acid serum level in early detection of bowel ischemia.

Method:This is a retrospective study conducted at King Abdulaziz University Hospital from August to October, 2016, enrolled all patients admitted with diagnosis of acute mesenteric bowel ischemia.

Result: Out of the 192 cases included in the study, 54.2\% of them were males, and $45.8 \%$ were females, with mean age score $60.9 \pm 17.3,46$ patients(24\%) were positive for bowel ischemiaand 21 cases out of them $(45.7 \%)$ had an operative notes Correlated with CT findings. 2 (1\%) cases had no correlation with CT findings, and the rest reported no operation. Less than quarter 44 patients $(22.9 \%)$ reported suffering from only bowl Ischemia without any risk factors or comorbidity, while 34 patients (17.7\%) reported a coexisting several risk factors and other diseases. Approximately 107 patients (55.7\%) had high lactic acid level. There was significant relation between lactic acid rang and CT scan findings where more than two third of the cases with positive CT had high lactic acid level (69.6\% high vs $30.4 \%$ normal, $\mathrm{p}=0.02)$

Conclusion: Further studies are needed to be conduct on the base of serial measurements of lactic acidosis and on a base combining serum lactate with other biomarkers such as intestinal fatty acidbinding protein to increase the accuracy of diagnosis.
\end{abstract}

Copy Right, IJAR, 2017,. All rights reserved.

\section{Introduction: -}

Acute mesenteric ischemia (AMI) define as" syndrome caused by inadequate blood flow through the mesenteric vessels, resulting in ischemia and eventual gangrene of the bowel wall". Although relatively rare, it is a potentially life-threatening condition (1). There are several diseases related to AMI such as acute arterial mesenteric ischemia, acute venous mesenteric ischemia, non-occlusive mesenteric ischemia, ischemia/reperfusion injury, ischemic colitis (2). 
There is high mortality rate due to AMI, ranging between 50-90\%, early diagnosis and treatment are essential to improve the outcome of Acute mesenteric ischemia (AMI) accounts for about 1:1000 acute hospital admissions. Untreated, AMI will cause mesenteric infarction, intestinal necrosis, an overwhelming inflammatory response and death, Early diagnosis and prompt treatment are the goals of modern therapy, but there are no randomized controlled trials to guide treatment and the published literature contains a high ratio of reviews to original data. Much of that data comes from case reports and often small, retrospective series with no clearly defined treatment criteria. (3)

Acute bowel ischemia has a wide range of possible clinical and pathological presentations since it can be caused by a variety of different conditions and presents with various clinical and radiological findings. Therefore, it may easily be missed or misinterpreted initially. (4) primarily because the diagnosis is usually based on nonspecific clinical symptoms. In spite of massive tissue necrosis, clinical symptoms are often atypical or lacking, many researchers have attempted to find a simple laboratory test that could identify ischemic bowel before irreversible damage occurs. (5)

Catheter angiography is unequivocally the gold standard imaging modality for the evaluation of AMI, However, it is invasive, expensive and time consuming, Color Doppler is also another helpful diagnostic tool but may be technically difficult in patients with AMI due to bowel gas. The introduction of spiral Computed Tomography (CT) improved the ability of CT to image the mesenteric vessels and the bowel wall but it still was not sensitive (64\%) for the early detection of AMI. (6)

Many potential serological markers have been investigated over the last decades, and several clinical reviews have been published. In general, these reviews are narrative, prone to the selection bias, and do not provide a comparison of diagnostic accuracy. (7)

The performance of the currently available serological markers is suboptimal for routine clinical use, but novel markers of intestinal ischemia such as D-lactate, glutathione S-transferase (GST), and intestinal fatty acidbinding protein(I-FABP) may offer improved diagnostic accuracy. (8)

Traditionally, the serum marker which clinicians frequently rely on is serum lactate. Still, the discrepancy between the common usage of serum lactate and the certainty of diagnosing acute mesenteric ischemia is extremely wide. The ideal marker for acute mesenteric ischemia should therefore not only have a higher sensitivity and specificity, but - most importantly - also enable earlier diagnosis. (9)

Several studies were conduct to investigate the relation between serum lactate and acute mesenteric ischemia, where the results showed that the level of no single serum marker, including serum lactate, is elevated early and specifically enough in the serum to diagnose acute mesenteric ischemia. $(7,8)$

Since that early diagnosis of intestinal ischemia remains a challenge, a further research is required to identify improved serological markers and to demonstrate their clinical utility in the individual patient (6) Our aim in this study is to identify the accuracy of using lactic acid in for early detection of bowel ischemia.

\section{Methodology: -}

This was a retrospective study conducted at King Abdul-Aziz University Hospital from August to October, 2016, enrolled all patients admitted with diagnosis of AMI (all types). The study protocol was reviewed and approved by King Abdul-Aziz University Hospital Health and Research Ethics. Inclusion criteria: patients aged more than 18 who underwent CT abdomen and pelvic without/with IV contrast and serum lactic acid to rule out bowel ischemia. The exclusion criteria include incomplete CT abdomen or missing serum lactic acid data. A total of 227 files were reviewed during the period, and only 192 files matching the inclusion criteria and enrolled in the study, while the rest were excluded for several reasons , 2 cases were less than the age of 18, and 33 cases hadn't complete information of serum lactic acid level. The Data were retrieved from patients' files and radiology PACS system using a data collection sheets included patient (age, gender, CT findings, operative notes, affected segment, type of bowl ischemia, duration of symptoms, other chronic illness, lactic acid level, examination time).

\section{Statistical analysis:-}

The collected data were analyzed using the SPSS statistical software package, version 20. Parametric data are presented as mean and standard deviations (minimum and maximum) and categorical data were presented as number 
(percentage). Relation between lactic acid range and other categorical variables was made using Chi - square test.Pearson's correlation between lactic acid andage was done. $P$-value $<0.05$ was considered significant.

\section{Results: -}

Out of the 192 cases included in the study, $54.2 \%$ of them were males, and $45.8 \%$ were females, with mean age score $60.9 \pm 17.3$ range (20-96) years. (Table 1\& Figures 1 \&2)

More than threequarter of CT scan reports 146 patients (76\%) were negative for bowel ischemia and other diagnosis such as inflammatory bowel disease and infectious colitis were confirmed, while 46 patients (24\%) were positive for bowel ischemia, from these cases $21(45.7 \%)$ had operative notesCorrelated with CT findings. Only 1patient (2.2\%) had no correlation with CT findings, and the rest reported cases did not undergo anoperation. (Tables 2 \& $3 \&$ Figures 3 \&4)

Regarding affected segment, type and symptoms duration, the majority of the cases 146 patients (76\%)reported no evidence of bowel ischemia while only 37 patients (19\%) reported multiple affected segments, on the other hand several types were reported in this study with different rate , 17 patients (8.9\%) reported as (Non occlusive intestinal ischemia.), follow by 9 patients (4.7\%) with chronic intestinal ischemia and 12 patients(6.2\%) are seen in acute superior mesenteric artery occlusion \&acute superior mesenteric vein occlusion. There are more than two third of the patients 133 patients $(67.8 \%)$ had the symptoms for less than 1 week, followed by 25 patients (12.8\%) cases had the symptoms for 2 weeks to 1 month . (Tables 4, 5 \&6\& Figures 5,6 \&7)

Less than quarter 44 patients $(22.9 \%)$ reported suffering from onlybowl Ischemia without any other diseases, while 34 patients $(17.7 \%)$ cases reported suffering from several comorbid diseases , 15 patients (7.8\%) cases reported organ failure , 12 patients $(6.35 \%)$ cases had lower limb ischemia.22 patients $(11.4 \%)$ divided equally between Other causes of acute abdomen\&Malignancy of other organs. There are 14patients $(7.2 \%)$ divided equally between cholecystitis\&bowel obstruction., and only 4 patients $(2.1 \%$ ) had Cholelithiasis. (Table 7\& Figure 8)

Regarding lactic acid and INR ranges and day \& night shifts at the time of the diagnosis, more than half (107$55.7 \%$ ) had high lactic acid level and almost half had high INR range (95- 49.5\%), in respect to the shifts 122 $(63.5 \%)$ cases reported positive during day shift while $70(36.5 \%)$ cases reported positive during night shift. (Tables 8\&9\& Figures 9,10,11 \&12)

There was significant relation between lactic acid rang and CT scan findings where more than two third of the cases with positive CT had high lactic acid level (69.6\% high vs $30.4 \%$ normal , $\mathrm{p}=0.02$ ), also there was significant relation between lactic acid rang and type $(\mathrm{p}=0.03)$, on the other hand the results showed high level of lactic acid among male than female, and also among patients who had duration of symptoms less than one week rather than patients who had the symptoms for almost a month with no significant difference . (Table 10)

Pearson correlation showed non-significant positive correlation between lactic acid and age.

Table 1:-Demographic data :

\begin{tabular}{|l|c|c|}
\hline variables & Mean \pm SD & (Min-Max) \\
\hline Age & $\mathbf{6 0 . 9} \pm \mathbf{1 7 . 3}$ & $\mathbf{( 2 0 - 9 6 )}$ \\
\hline Variables & $\mathbf{N}$ & $\mathbf{\%}$ \\
\hline $\begin{array}{l}\text { Gender } \\
\text { Male }\end{array}$ Female & 104 & 54.2 \\
\cline { 2 - 3 } & 88 & 45.8 \\
\hline
\end{tabular}



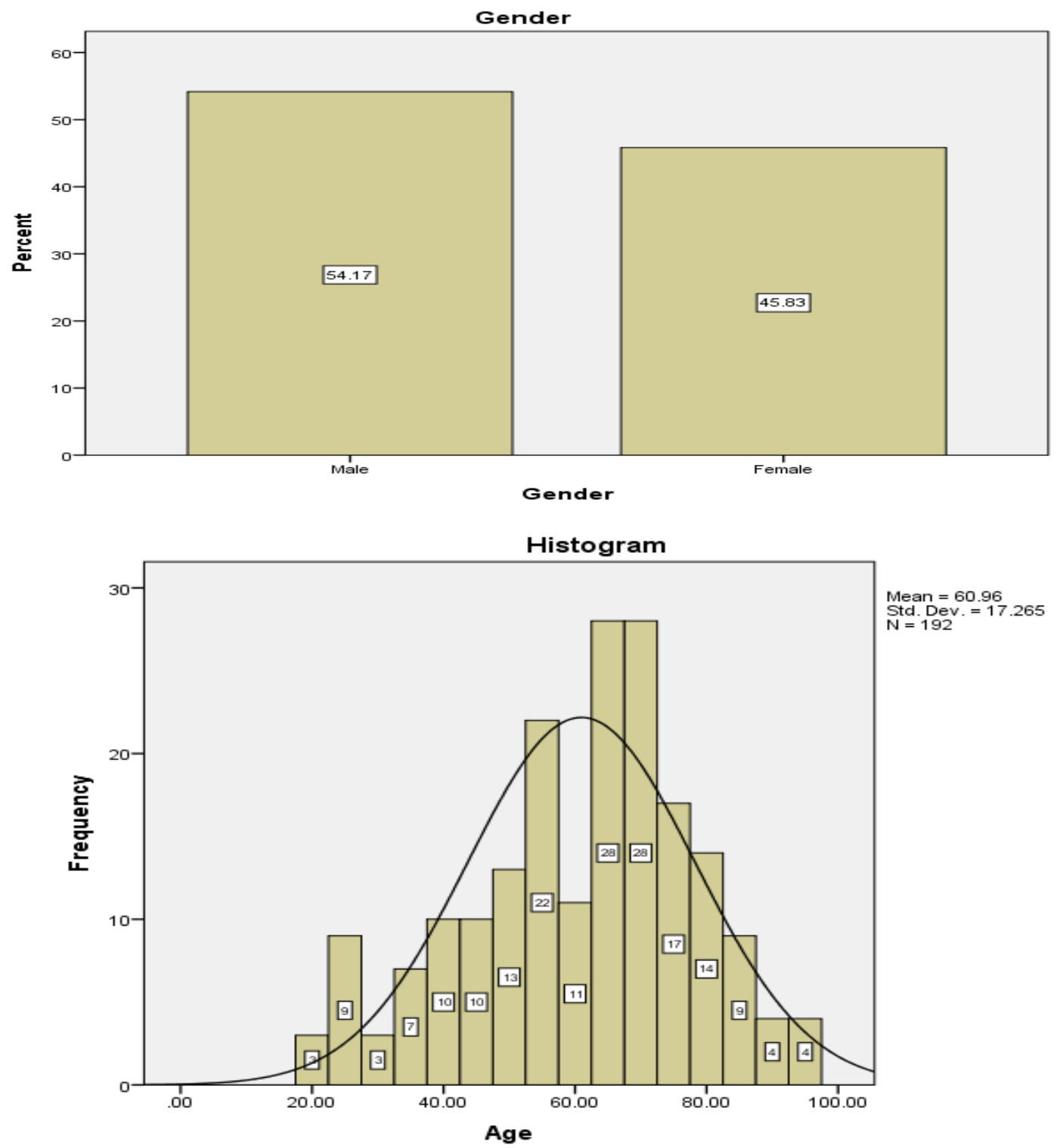

Table 2:-CT:

\begin{tabular}{|l|c|c|}
\hline Variables & $\mathrm{N}$ & $\%$ \\
\hline (+ve) suggestive of bowel ischemia & 46 & 24.0 \\
\hline $\begin{array}{l}\text { (-ve) other diagnosis (inflammatory bowel disease } \\
\text { and infectious colitis.....). }\end{array}$ & 146 & 76.0 \\
\hline
\end{tabular}




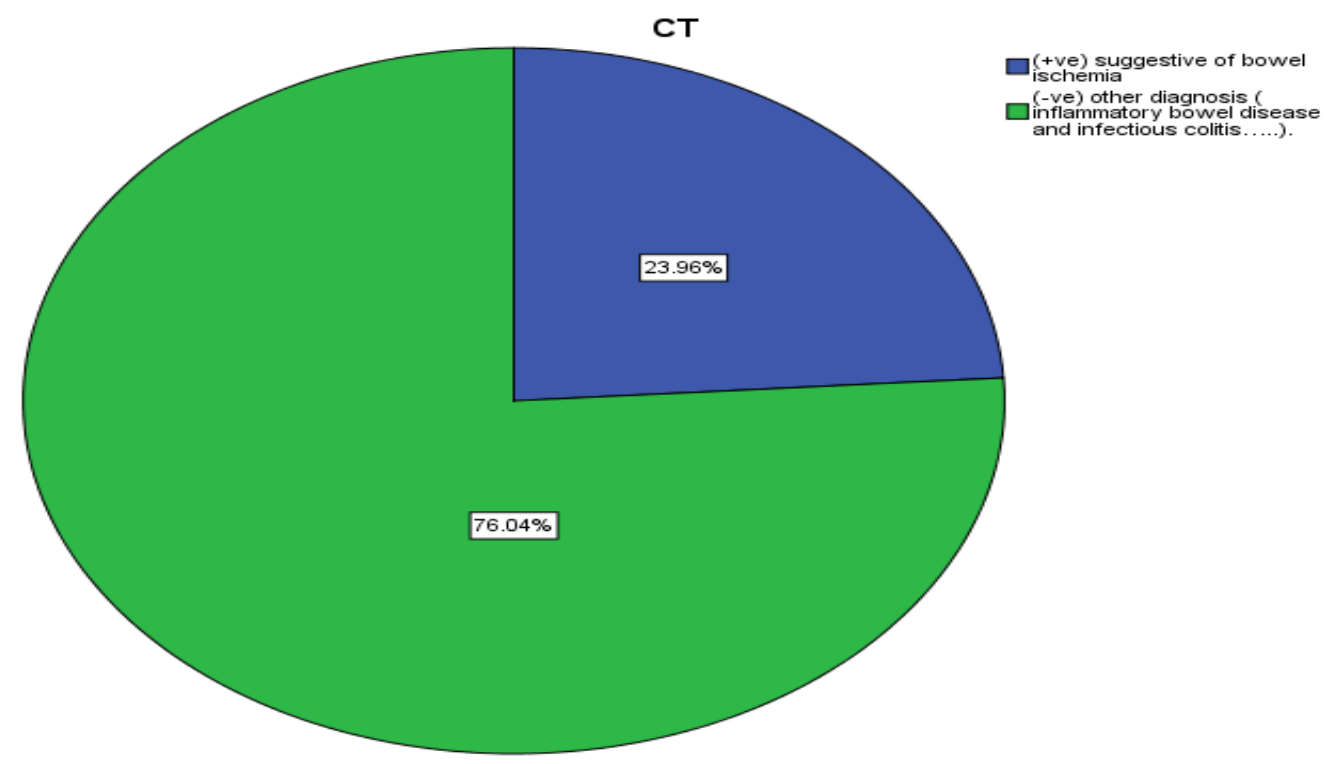

Table 3:- Operative notes.

\begin{tabular}{|l|c|c|}
\hline Variables (N=46) & N & $\%$ \\
\hline Correlated with CT findings. & 21 & 45.7 \\
\hline No correlation with CT findings. & 1 & 2.2 \\
\hline No operation done for bowel ischemia. & 24 & 52.1 \\
\hline
\end{tabular}

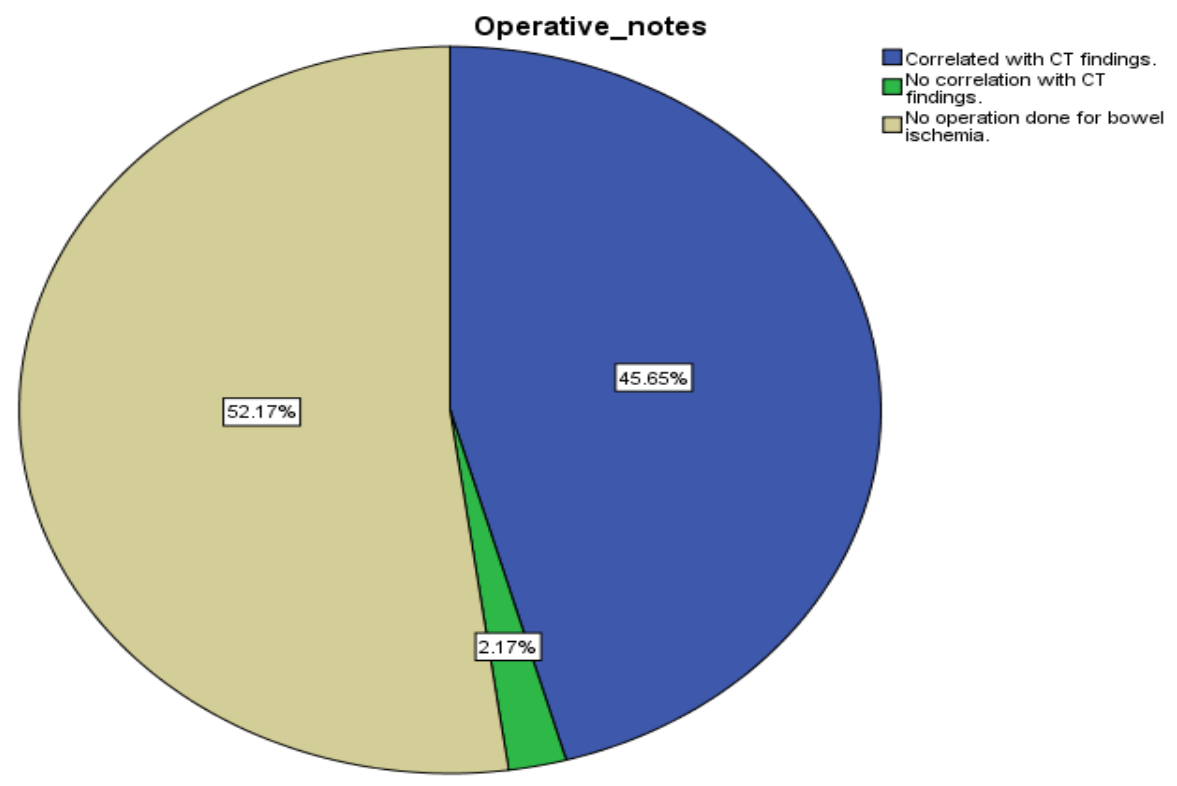

Table 4:-Affected segment.

\begin{tabular}{|l|c|c|}
\hline Variables & N & $\%$ \\
\hline No segment affected & 146 & 76.8 \\
\hline Duodenal segment & 1 & .4 \\
\hline Jejonul segment & 3 & 1.4 \\
\hline Iliul segment & 3 & 1.4 \\
\hline Multi & 37 & 19.0 \\
\hline Unknown & 2 & 1 \\
\hline
\end{tabular}




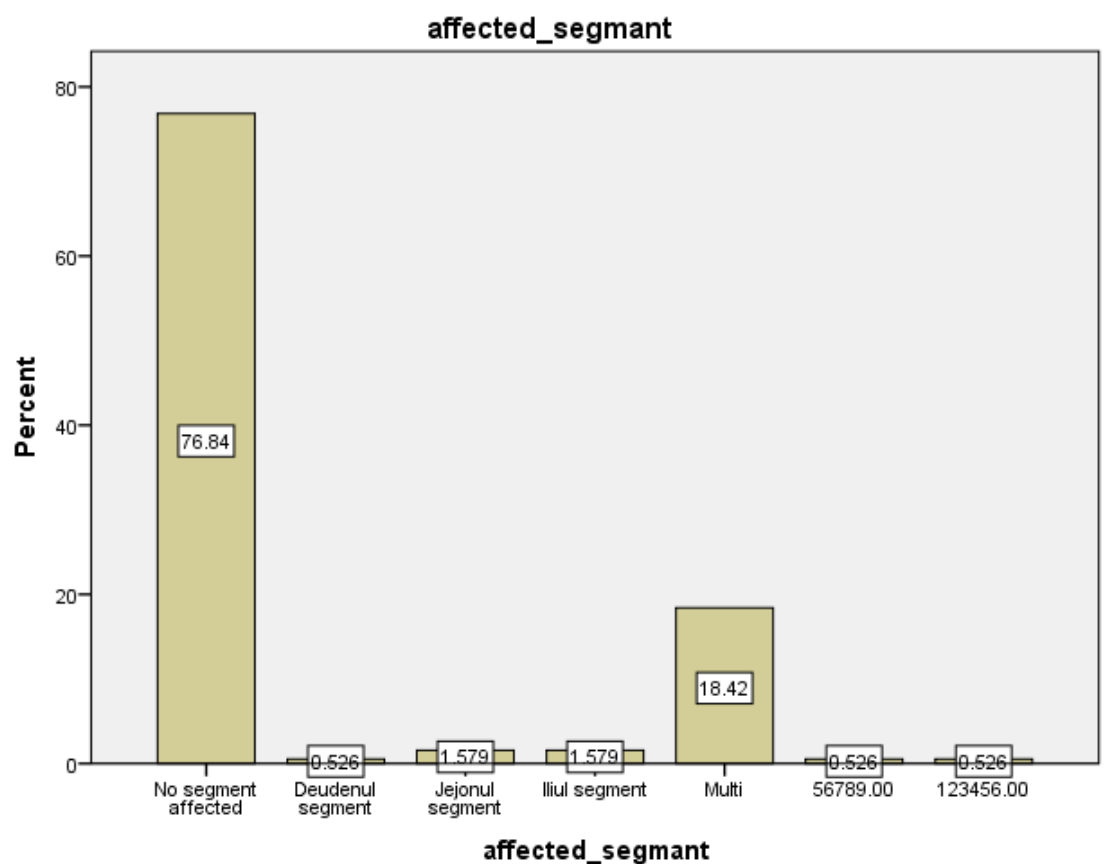

Table 5:- Type.

\begin{tabular}{|l|c|c|}
\hline Variables & $\mathrm{N}$ & $\%$ \\
\hline No bowel ischemia detected & 146 & 76.0 \\
\hline acute superior mesenteric artery occlusion & 6 & 3.1 \\
\hline acute superior mesenteric vein occlusion & 6 & 4.1 \\
\hline chronic intestinal ischemia & 9 & 8.7 \\
\hline Non-occlusive intestinal ischemia. & 17 & 1.6 \\
\hline Occlusive intestinal ischemia. & 3 & 2.1 \\
\hline $\begin{array}{l}\text { Mesenteric ischemia 2ndry to obstruction; (tumour, } \\
\text { incarcerated hernia...) }\end{array}$ & 4 & 0.5 \\
\hline Unknown & 1 & \\
\hline
\end{tabular}

Type

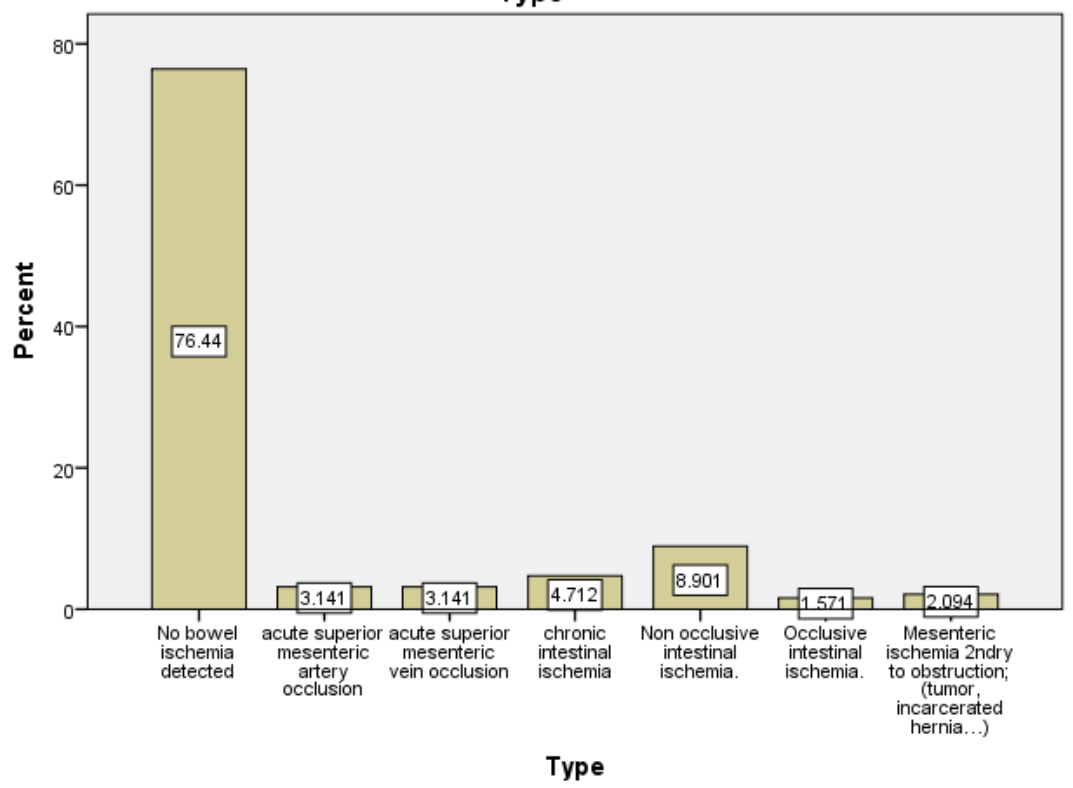


Table 6:-Duration of symptoms.

\begin{tabular}{|l|c|c|}
\hline Variables & $\mathrm{N}$ & $\%$ \\
\hline$<1$ week & 133 & 67.8 \\
\hline 1 week & 16 & 8.2 \\
\hline 2 weeks to one month. & 25 & 12.8 \\
\hline $1-3$ months. & 9 & 4.6 \\
\hline $\begin{array}{l}\text { NO SYMPTOMS DETECTED (CT ordered for } \\
\text { confirmation or exclusion). }\end{array}$ & 6 & 3.1 \\
\hline unknown & 3 & 1.5 \\
\hline
\end{tabular}

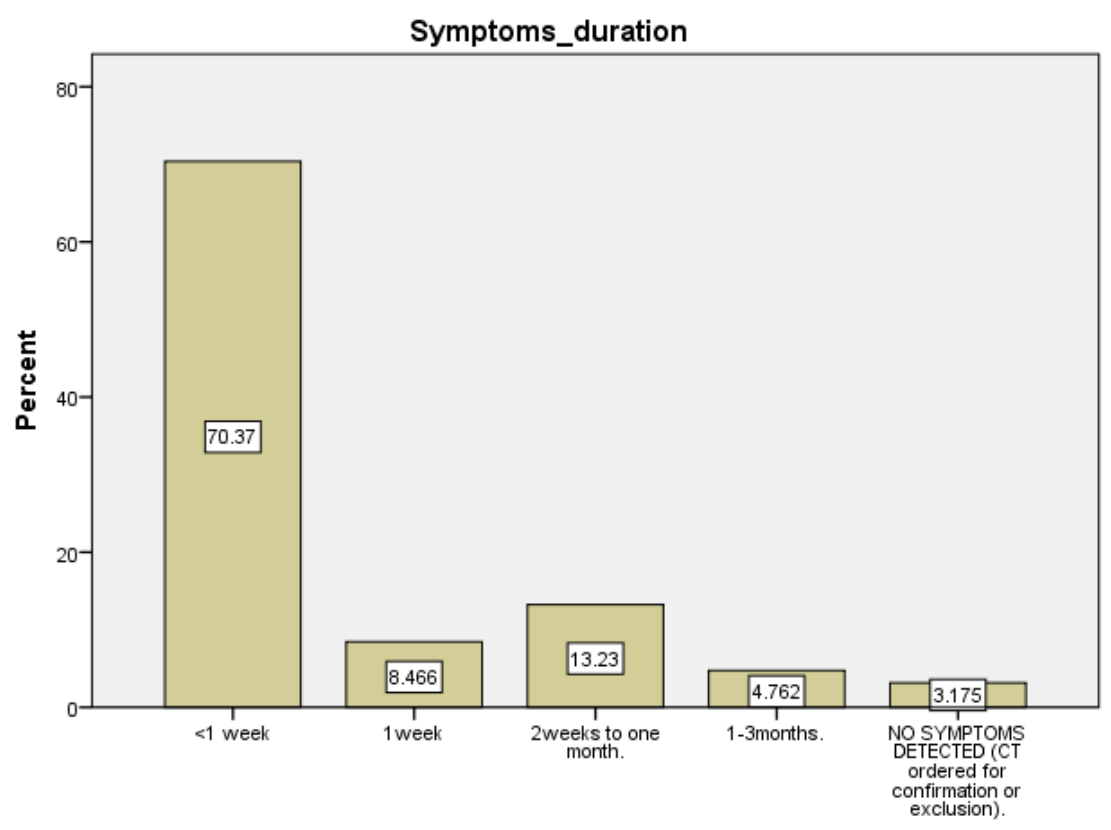

Symptoms_duration

Table 7:-Other differential diagnosis:

\begin{tabular}{|l|c|c|}
\hline Variables & N & $\%$ \\
\hline Bowel ischemia. & 44 & 22.9 \\
\hline cholecystitis & 7 & 3.6 \\
\hline Cholelithiasis. & 4 & 2.1 \\
\hline Small or large bowel obstruction. & 7 & 3.6 \\
\hline $\begin{array}{l}\text { Other causes of acute abdomen ; Pancreatitis, peptic ulcer } \\
\text { disease, appendicitis, bowel volvulus }\end{array}$ & 5.7 \\
\hline Systemic and autoimmune diseases; SLE & 2 & 1.0 \\
\hline Multiple morbidities ( ESRD, HTN, CHF....) & 4 & 2.1 \\
\hline Malignancy of other organs; liver, pancreas... & 11 & 5.7 \\
\hline Blood disorders ; anaemia, DIC... & 3 & 1.6 \\
\hline Shock & 6 & 3.1 \\
\hline $\begin{array}{l}\text { Ischemic disorders in the peripheries and organs other than } \\
\text { the intestine (brain, heart, lung, liver, stroke....) }\end{array}$ & 12 & 6.3 \\
\hline Hernia & & 1.6 \\
\hline Infectious disease; sepsis, TB, pseudomonas colitis.... & 3 & 8.9 \\
\hline $\begin{array}{l}\text { Renal disorders ; calculus of kidney, hydronephrosis, ureteral } \\
\text { stones... }\end{array}$ & 17 & 3.1 \\
\hline Organ failure; heart, renal, liver... & 6 & 7.8 \\
\hline Unspecified diagnosis. & 15 & 3.1 \\
\hline Multi & 6 & 17.7 \\
\hline
\end{tabular}




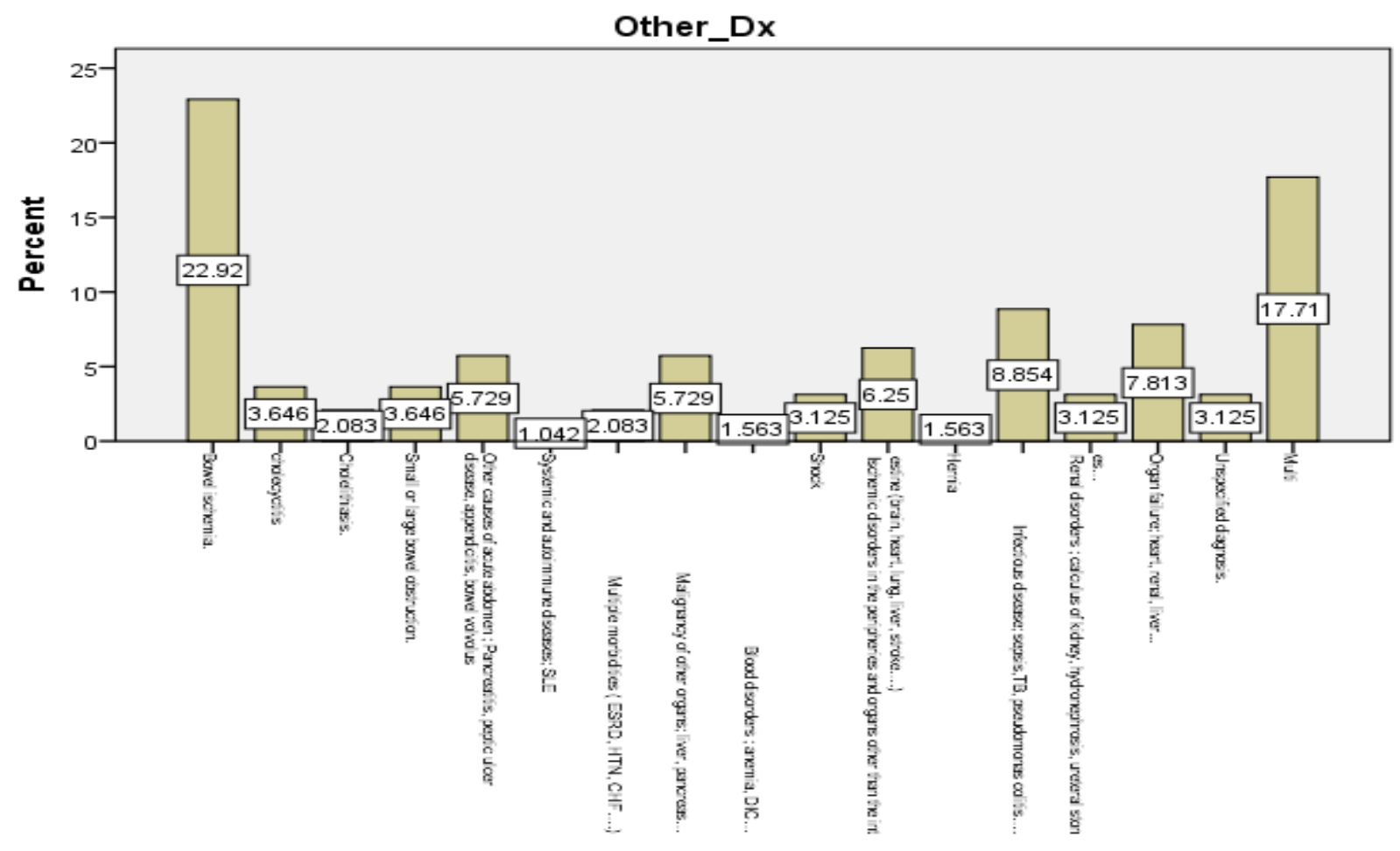

Table 8:-Lactic acid and INR range.

\begin{tabular}{|l|c|c|}
\hline Variables & $\mathbf{N}$ & \% \\
\hline Lactic acid range & & 44.3 \\
\hline Normal & 85 & 55.7 \\
\hline High & 107 & 2.1 \\
\hline $\begin{array}{l}\text { INR range } \\
\text { None }\end{array}$ & 4 & 48.4 \\
\cline { 2 - 3 } $\begin{array}{l}\text { The normal range in healthy people is 1.1 or below. } \\
\text { An INR range of 2.0 to 3.0 is generally an effective } \\
\text { therapeutic range for people taking warfarin }\end{array}$ & 93 & 49.5 \\
\cline { 2 - 3 }
\end{tabular}

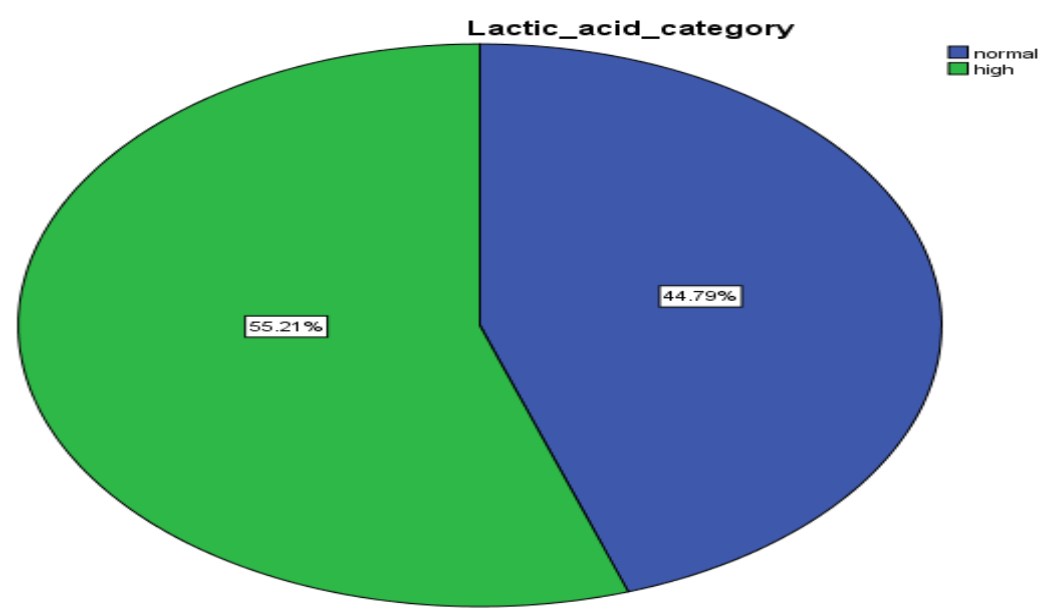




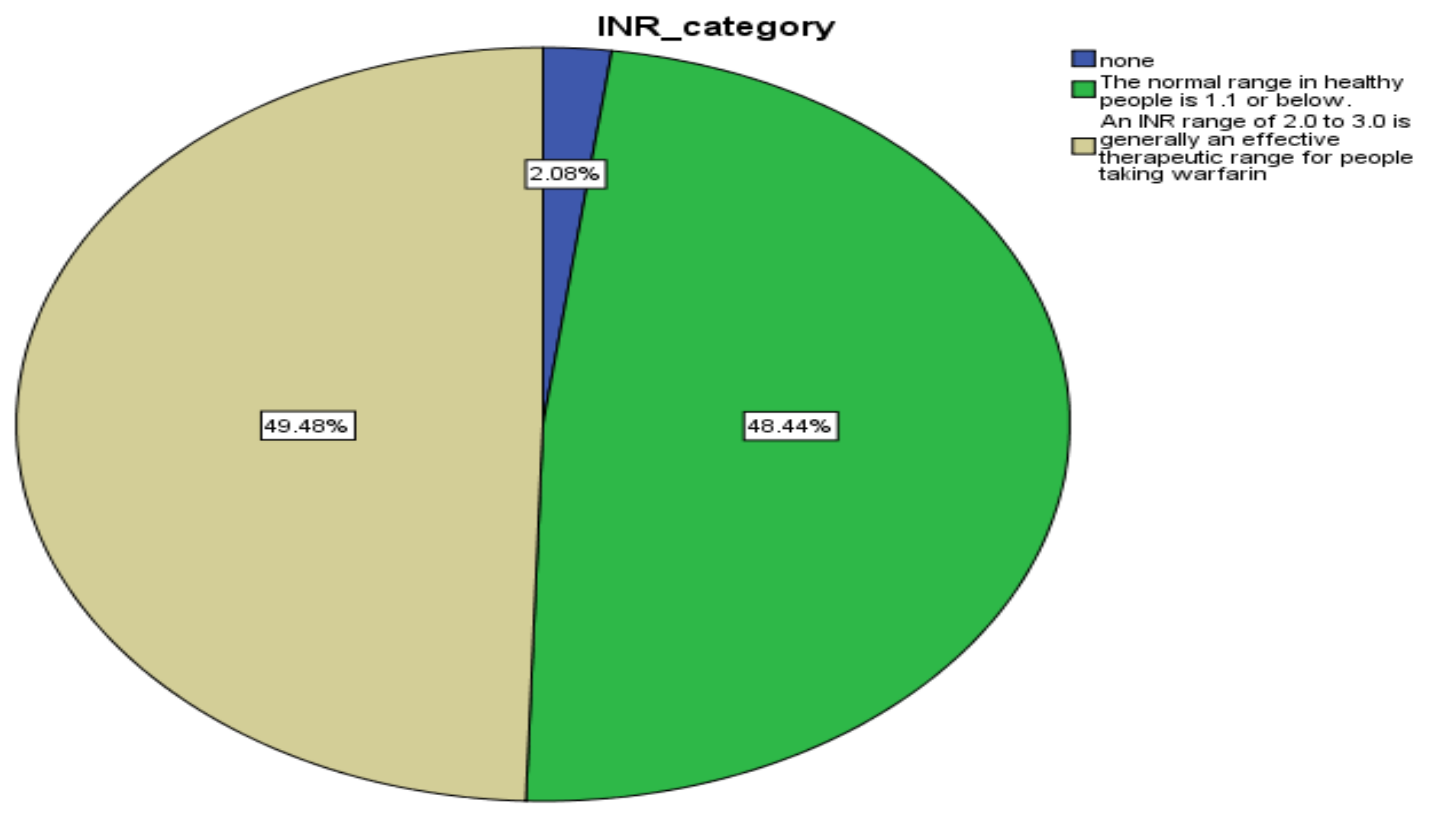

Table 9:-Day and night shifts :

\begin{tabular}{|l|c|c|}
\hline Variables & $\mathrm{N}$ & $\%$ \\
\hline \multirow{2}{*}{$\begin{array}{l}\text { Day shifts } \\
\text { negative } \\
\text { positive }\end{array}$} & 70 & 36.5 \\
\hline $\begin{array}{l}\text { Night shifts } \\
\text { negative } \\
\text { positive }\end{array}$ & 122 & 63.5 \\
\cline { 2 - 3 } & 122 & 63.5 \\
\cline { 2 - 3 } & 70 & 36.5 \\
\hline
\end{tabular}

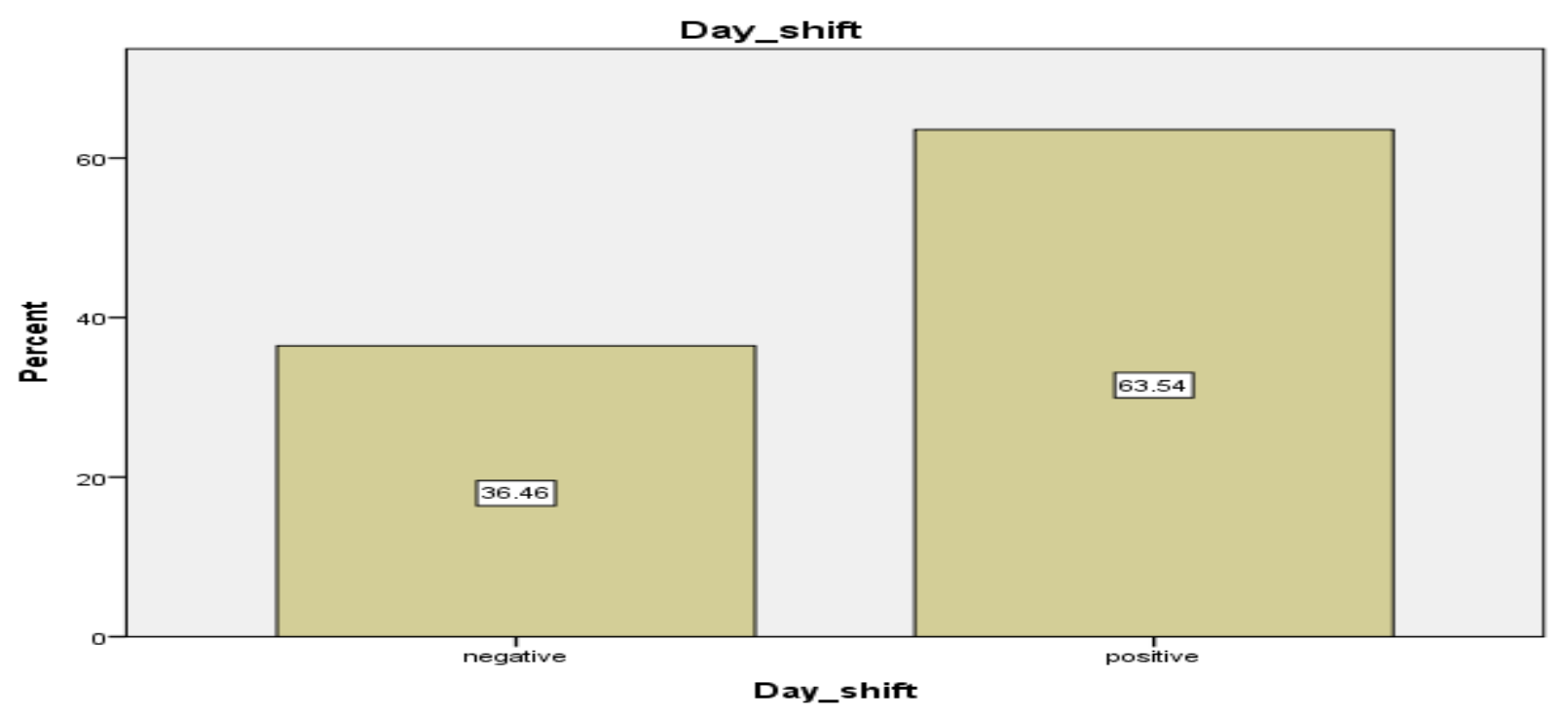




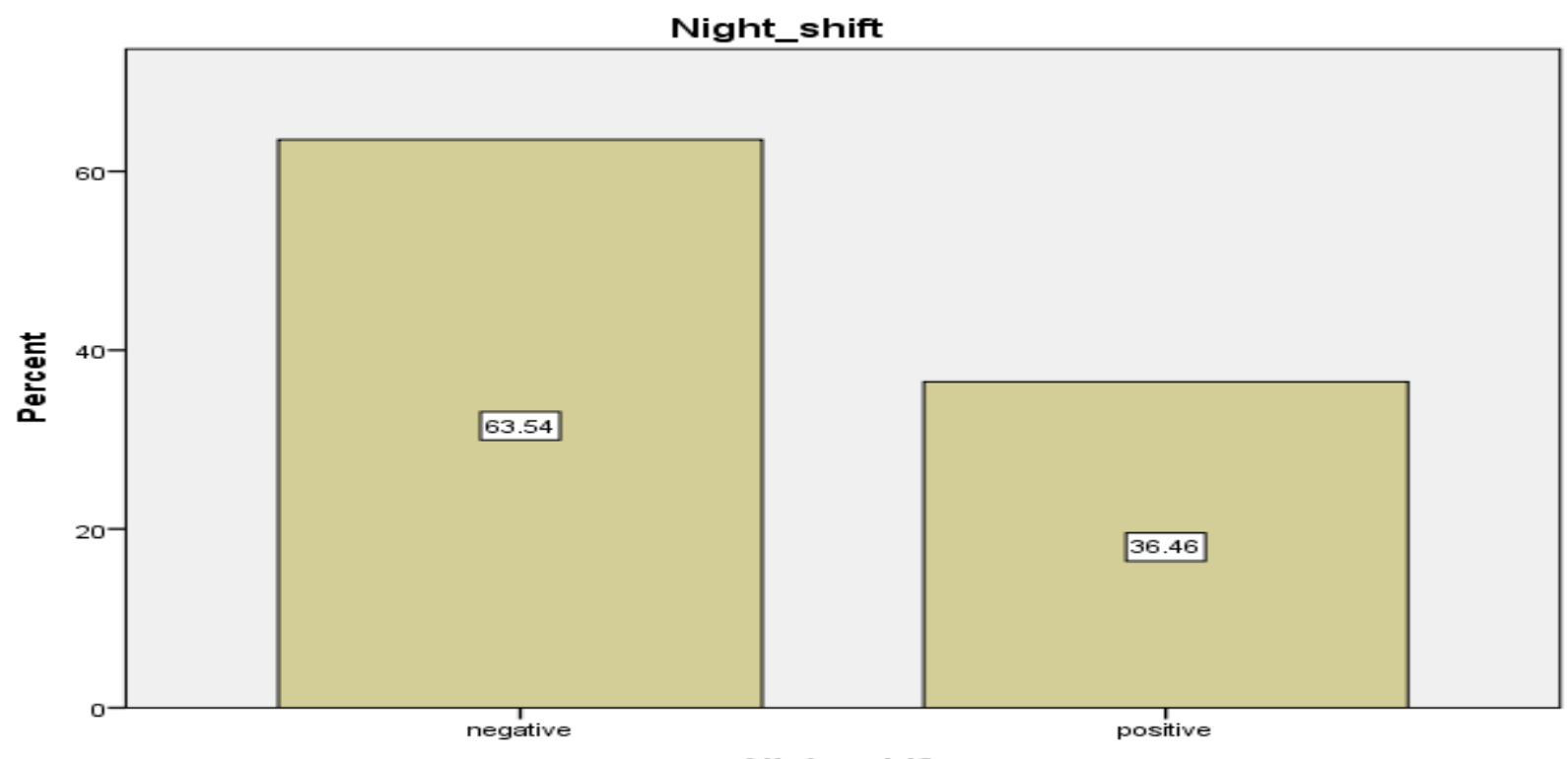

Night_shift

Table 10:-Relation between lactic acid and several factors :

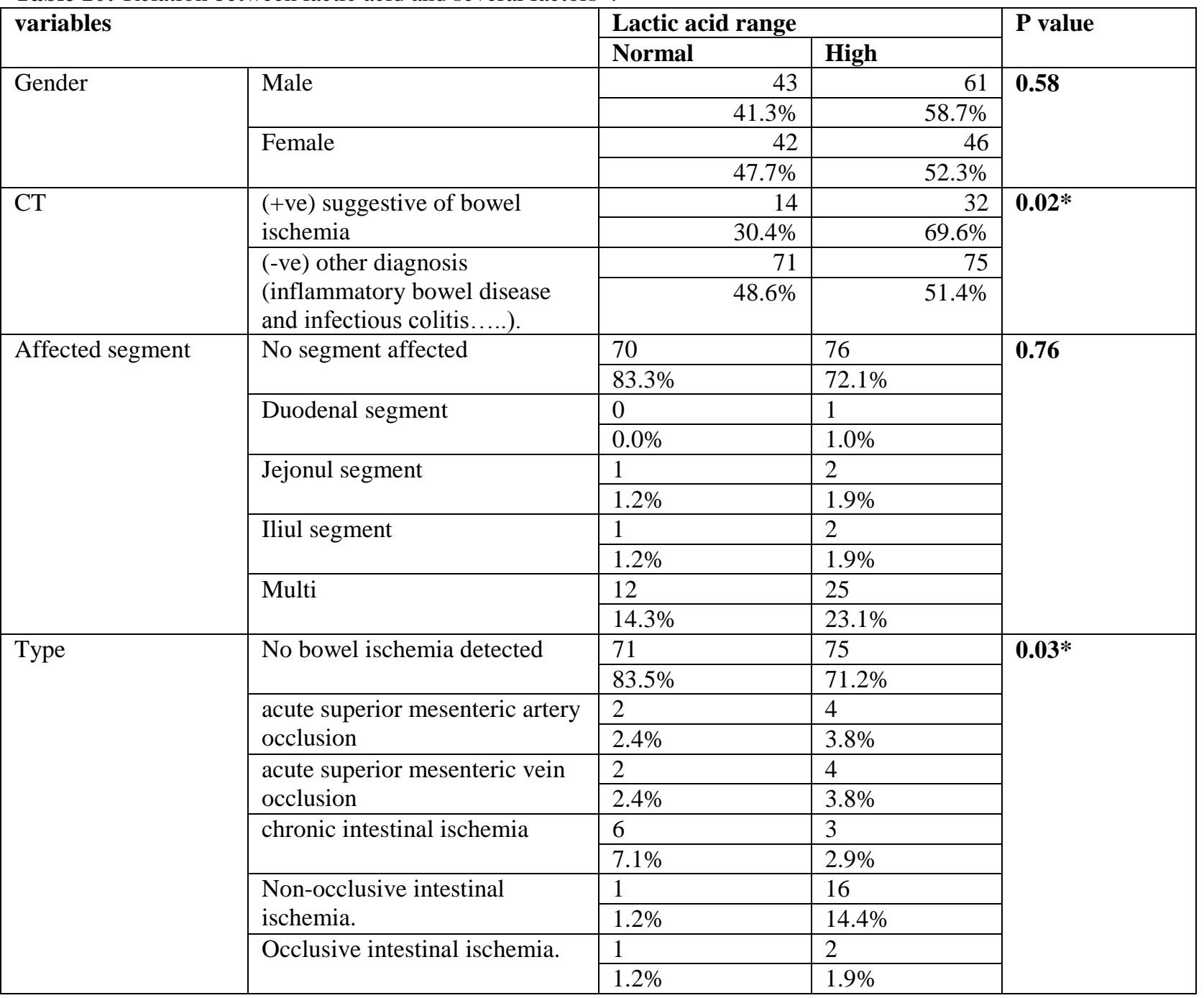




\begin{tabular}{|c|c|c|c|c|}
\hline & \multirow{2}{*}{$\begin{array}{l}\text { Mesenteric ischemia 2ndry to } \\
\text { obstruction; (tumour, } \\
\text { incarcerated hernia...) }\end{array}$} & 2 & 2 & \\
\hline & & $2.4 \%$ & $1.9 \%$ & \\
\hline \multirow[t]{10}{*}{ Symptoms duration } & \multirow[t]{2}{*}{$<1$ week } & 57 & 76 & \multirow[t]{10}{*}{0.76} \\
\hline & & $67.9 \%$ & $72.8 \%$ & \\
\hline & \multirow[t]{2}{*}{ 1week } & 10 & 6 & \\
\hline & & $11.9 \%$ & $4.9 \%$ & \\
\hline & \multirow[t]{2}{*}{2 weeks to one month. } & 10 & 15 & \\
\hline & & $11.9 \%$ & $14.6 \%$ & \\
\hline & \multirow[t]{2}{*}{ 1-3months. } & 4 & 5 & \\
\hline & & $4.8 \%$ & $4.9 \%$ & \\
\hline & \multirow{2}{*}{$\begin{array}{l}\text { NO SYMPTOMS DETECTED } \\
\text { (CT ordered for confirmation or } \\
\text { exclusion). }\end{array}$} & 3 & 3 & \\
\hline & & $3.6 \%$ & $2.9 \%$ & \\
\hline \multirow[t]{6}{*}{ Operative notes } & \multirow[t]{2}{*}{ Correlated with CT findings. } & 15 & 15 & \multirow[t]{6}{*}{0.42} \\
\hline & & $17.6 \%$ & $14.3 \%$ & \\
\hline & \multirow{2}{*}{$\begin{array}{l}\text { No correlation with CT } \\
\text { findings. }\end{array}$} & 1 & 1 & \\
\hline & & $1.2 \%$ & $1.0 \%$ & \\
\hline & \multirow{2}{*}{$\begin{array}{l}\text { No operation done for bowel } \\
\text { ischemia. }\end{array}$} & 69 & 91 & \\
\hline & & $81.2 \%$ & $84.8 \%$ & \\
\hline
\end{tabular}

Table 11;- Correlation between lactic acid and age and INR :

\begin{tabular}{|l|l|r|r|r|}
\hline \multicolumn{2}{|c|}{} & \multicolumn{1}{|c|}{ Age } & Lactic acid & \multicolumn{1}{c|}{ INR } \\
\hline \multirow{5}{*}{ Age } & Pearson Correlation & 1 & .012 & $-.16-^{*}$ \\
\cline { 2 - 5 } & Sig. (2-tailed) & & .864 & .025 \\
\cline { 2 - 5 } & $\mathrm{N}$ & 192 & 192 & 188 \\
\hline \multirow{5}{*}{ Lactic acid } & Pearson Correlation & .012 & 1 & $.207^{* *}$ \\
\cline { 2 - 5 } & Sig. (2-tailed) & .864 & & .004 \\
\cline { 2 - 5 } & $\mathrm{N}$ & 192 & 192 & 188 \\
\hline & Pearson Correlation & $-.164-{ }^{*}$ & $.207^{* *}$ & 1 \\
\cline { 2 - 5 } & Sig. (2-tailed) & .025 & .004 & 188 \\
\cline { 2 - 5 } & $\mathrm{N}$ & 188 & 188 & \\
\hline
\end{tabular}

\section{Discussion: -}

AMI consists of two varied pathophysiological existence diagnostic \& treatment, while the treatment consist of instrumental arterial reperfusion and resection of necrotic bowel segments, still the diagnosis had several challenges \& difficulties due to the fact that patients could be admitted to the ER without specific symptoms of abdominal pain , $(2,10)$ In two thirds of the cases the cause of intestinal ischemia were "arterial embolism or thrombosis with blood flow impairment in the superior mesenteric artery (SMA) distribution affecting all or portions of the small bowel and right colon" which increase CT-scandisparity, (2)

The fact that there is diagnostic uncertainty regarding variety in the results of symptoms, laboratory tests, and radiological imaging demonstrate the essential need to find an early dependable diagnostic tool in order to diagnoseintestinal ischemia as soon as possible to reduce the mortality rate motivate a lot of researchers to investigate more and more to find this tool. A study conducted in 2009 by Evennett et al, the authors recommended the use of serological markerssuch as D-lactate, GST, andI-FABPand study their accuracy in diagnosis $(2,11)$

Where the pathophysiology of acute mesenteric ischemia is the decreasing in mesenteric blood flow which induce cells dying, these necrotic cells in the gut wall release chemical substances to the blood, by detecting these substances which serum lactate is one of them, doctors could diagnose acute mesenteric ischemia early, however this hypothesis didn't take to the account the other causes of increasing serum lactate level such as damaged liver or kidney function in sepsis and shock, agents that can uncouple oxidative phosphorylation ( toxins, drugs) or underlying disorders change lactate metabolism (congenital mitochondrial disorders, diabetes, malignancies). (7) 
several studies (case series, experimental and prospective) since 1970s conduct to investigate the effectiveness of using serum lactate levels changes as a reliable biomarker of AMI. $(12,13)$

One of the early case series study to detect the relation between high serum lactate level and AMI was the study of Janda et alin 1984 followed by Nutz and Sommer study in 1987, where the author of both studies demonstrated increasing in the level of serum lactate among AMI patients and explained that by the increasing in demands of blood and oxygen by intestine and increase the depending on anaerobic metabolism causing acidosis and a serum lactic acid increase (lactacidemia), however both studies didn't include time factor between onset of ischemia and time of diagnosis . $(7,14,15$,$) On the other hand, in USA study the authors addressed several factors influence the$ effectiveness of the markers: site, amount, releasing mechanism, separating from the serum and specificity for the intestine. (16) These kinds of studies continue during the $21^{\text {st }}$ century where some studies confirmed the relation and others didn't confirm the relation. $(17,18)$

Several experimental studies were conduct with debatable findings and without providing conclusive evidences of the efficacy of using serum lactate level as marker for AMI, in study on rabbits by Nutz et al, the authors observed increasing in the level of serum lactate among the subjects with occlusion of the superior mesenteric artery, these results couldn't be confirmed in 1995 study on pigs conducted by Schlichting and Lyberg, $(19,20)$ In addition to that several experimental studies during the first decade of $21^{\text {st }}$ century concluded that serum lactate level is not a specific and early diagnostic marker for AMI. $(13,21,22)$

Several prospective clinical studies on lactate levels andacute mesenteric ischemia were conduct, from these studies the two studies conduct 1994 and 1997 by Lange and Jackel and also Lange and Toivola where the authors concluded that even with the high sensitivity of serum lactate the specificity was low which mean that doctors couldn't rely on serum lactate as specific markers. $(7,23,24)$, during the last few years the number of prospective studies comparing the accuracy of several biomarkers were increased and demonstrated the fact that that none of the using biomarkers had the level of accuracy to be used alone as diagnostic markers. $(25,26)$, in 2015 a study was conduct to assess the accuracy of repeated measurement of serum lactate as a marker and the authors reported that there are several factors influenced this accuracy. (12) The results of current study consistence with previous study results that serum lactate is not accurate as the doctors want and need to be combine with other markers to diagnose AMI, however still a lot of doctors rely on serum lactate as diagnostic tool due to the facts that there is no good biomarkers could replace it, it is easy to measure in any laboratory hospital and easy to repeat it . $(7,12)$

During 2009 Evennett et alconduct acomparative analysis study of all major serum markersof acute mesenteric ischemia and they demonstrated D -lactate as the best markers , $(6,7)$ after that in 2015 study conducted by the authors reported that the D-lactate is a good markers for sever cases with high level of specificity, and recommend to combine it with I-FABP which has high sensitivity and low specificity. (11)

\section{Conclusion: -}

In the second decade of 21 st century, still there is a serious difficulty to find dependable diagnostic biomarker to diagnose acute mesenteric ischemia in early stage, this fact led doctors to rely onserum lactate level as a marker of acute mesenteric ischemia even that the evidence showed that it is unspecific marker for early detection. However, this study depends on measuring lactate level of one time only, further studies need to be conduct on a base of serial measurements of lactic acidosis and on a base combining serum lactate with other biomarkers to increase the accuracy of diagnosis.

\section{References:-}

1. http://emedicine.medscape.com/article/189146-overview

2. Reginelli A, Iacobellis F, Berritto D, Gagliardi G, Di Grezia G, Rossi M, Fonio P, Grassi R. Mesenteric ischemia: the importance of differential diagnosis for the surgeon. BMC surgery. 2013 Oct 8;13(2):1.

3. Tilsed JV, Casamassima A, Kurihara H, Mariani D, Martinez I, Pereira J, Ponchietti L, Shamiyeh A, Al-Ayoubi F, Ceolin M, D'Almeida AJ. ESTES guidelines: acute mesenteric ischaemia. European Journal of Trauma and Emergency Surgery. 2016 Apr 1;42(2):253-70.

4. Barmase M, Kang M, Wig J, Kochhar R, Gupta R, Khandelwal N. Role of multidetector CT angiography in the evaluation of suspected mesenteric ischemia. European journal of radiology. 2011 Dec 31;80(3):e582-7 
5. Stefan Acosta - Torbjo"rn Nilsson, Current status on plasma biomarkers for acute mesenteric ischemia, J Thromb Thrombolysis. 2012 May;33(4):355-61. doi: 10.1007/s11239-011-0660-z.

6. Evennett NJ, Petrov MS, Mittal A, Windsor JA. Systematic review and pooled estimates for the diagnostic accuracy of serological markers for intestinal ischemia. World journal of surgery. 2009 Jul 1;33(7):1374-83.

7. Demir IE, Ceyhan GO, Friess H. Beyond lactate: is there a role for serum lactate measurement in diagnosing acute mesenteric ischemia?. Digestive surgery. 2012 Jun 13;29(3):226-35.

8. Murray MJ, Gonze MD, Nowak LR, Cobb CF. Serum D (-)-lactate levels as an aid to diagnosing acute intestinal ischemia. The American journal of surgery. 1994 Jun 30;167(6):575-8.

9. Reginelli, A., et al. "Intestinal Ischemia: US-CT findings correlations." Crit Ultrasound J 5.Suppl 1 (2013): S7.

10. Bourcier S, Oudjit A, Goudard G, Charpentier J, Leblanc S, Coriat R, Gouya H, Dousset B, Mira JP, Pène F.Diagnosis of non-occlusive acute mesenteric ischemia in the intensive care unit. Ann Intensive Care. 2016 Dec;6(1):112.

11. Shi H, Wu B, Wan J, Liu W, Su B.The role of serum intestinal fatty acid binding protein levels and D-lactate levels in the diagnosis of acute intestinal ischemia. Clin Res Hepatol Gastroenterol. 2015 Jun;39(3):373-8.

12. Studer P, Vaucher A, Candinas D, Schnüriger B. The Value of Serial Serum Lactate Measurements in Predicting the Extent of Ischemic Bowel and Outcome of Patients Suffering Acute Mesenteric Ischemia. J Gastrointest Surg. 2015 Apr;19(4):751-5.

13. van Noord D1, Mensink PB, de Knegt RJ, Ouwendijk M, Francke J, van Vuuren AJ, Hansen BE, Kuipers EJ. Serum Markers and Intestinal Mucosal Injury in Chronic Gastrointestinal Ischemia. Dig Dis Sci. 2011 Feb;56(2):506-12.

14. Janda A, Hagmuller GW, Denck H: Lactate in the diagnosis of acute intestinal vascular

15. occlusions (in German). Chirurg 1984; 55: 469-473.

16. Nutz V, Sommer HJ: Hyperlactacidemia in intestinal ischemia. I. Theoretical considerations ) in German). Langenbecks Arch Chir 1987; 370: 63-68.

17. Thompson JS, Bragg LE, West WW: Serum enzyme levels during intestinal ischemia.Ann Surg 1990; 211: 369-373.

18. Kurimoto Y, Morishita K, Fukada J, Kawaharada N, Komatsu K, Yama N, Asai Y, Abe T:A simple but useful method of screening for mesenteric ischemia secondary to acute aorticdissection. Surgery 2004; 136: 42-46.

19. Akutsu K, Matsuda H, Sasaki H, Minatoya K, Ogino H, Kasai S, Tamori Y, Yokoyama N, Nonogi H, Takeshita S: A case of acute type B aortic dissection: limited role of laboratorytesting for the diagnosis of mesenteric ischemia. Ann Thorac Cardiovasc Surg 2007; 13:360-364.

20. Nutz V, Sommer JH, Schultze-Petzold J: Hyperlactacidemia in intestinal ischemia. II.Experimental principles (in German). Langenbecks Arch Chir 1987; 370: 69-78.

21. Schlichting E, Lyberg T: Monitoring of tissue oxygenation in shock: an experimental studyin pigs. Crit Care Med 1995; 23: 1703-1710.

22. Kurimoto Y, Kawaharada N, Ito T, Morikawa M, Higami T, Asai Y. An experimental evaluation of the lactate concentration following mesenteric ischemia. Surg Today. 2008;38:926-930.

23. Acosta S, Nilsson TK, Malina J, Malina M. L-lactate after embolization of the superior mesenteric artery. J Surg Res. 2007;143:320-328.

24. Lange H, Jackel R: Usefulness of plasma lactate concentration in the diagnosis of acuteabdominal disease. Eur J Surg 1994; 160: 381-384.

25. Huwer H, Winning J, Straub U, Isringhaus H, Kalweit G: Clinically diagnosed nonocclusivemesenteric ischemia after cardiopulmonary bypass: retrospective study. Vascular 2004; 12: 114-120.

26. Block T, Nilsson TK, Bjorck M, Acosta S: Diagnostic accuracy of plasma biomarkers forintestinal ischaemia. Scand J Clin Lab Invest 2008; 68: 242-248.

27. Gearhart SL, Delaney CP, Senagore AJ, Banbury MK, Remzi FH, Kiran RP, Fazio VW: Prospective assessment of the predictive value of alpha-glutathione S-transferase for intestinal ischemia. Am Surg 2003; 69: 324-329, discussion 329. 